\title{
Harnessing Renewable Energy at Kalasalingam Academy of Research and Education - A Role Model Case
}

\author{
Neelakandan T.R. ${ }^{1,}{ }^{*}$, Pandiyarajan $V^{2}$, Shasi Anand Sridharan ${ }^{3}$, Nagaraj Ramrao ${ }^{4}$ \\ 1,2,3,4 Kalasalingam Academy of Research and Education, Krishnankoil 626126, India \\ *corresponding author: neelakantan@klu.ac.in
}

\section{Article Info}

Received:
15 March 2021
Accepted:
25 May 2021
Published:
1 June 2021
DOI:
https://doi.org/10.14710/j
sp.2021.11201

Received:

Accepted:

25 May 2021

Published

021.11201

\begin{abstract}
Global energy demand and environmental concerns are the driving force for the use of alternative sustainable and ecofriendly renewable energy sources. Solar energy is the inexhaustible and $\mathrm{CO}_{2}$ emission free energy source worldwide. It produces significant environmental benefits in comparison to the conventional energy sources, thus contributing to the sustainable development of human activities. It produces clean and renewable power from the sun and benefits the environment without causing air and water pollution. Alternatives to fossil fuels reduce carbon foot print across the globe reducing emission of greenhouse gases and become ecofriendly. Solar power has attracted the largest share of new investments in solar energy across the world. This research article shows light on the solar energy sources developed by Kalasalingam Academy of Research and Education (KARE) for the effective utilization of solar energy in the campus and its impact on the reduction in carbon foot print and also the impact of green vegetation as a source of carbon sink for an ecofriendly campus.
\end{abstract}

\section{Keyword:}

Renewable energy, Greenhouse gases, Carbon footprint, Sustainable,

Carbon sink.

\section{Introduction}

Renewable energy sources supply $33 \%$ of the total world energy demand [1]. It includes solar, wind, biomass, geothermal and hydropower. They are the clean, inexhaustible, $\mathrm{CO} 2$ emission-free energy resources [2,3]. In the Global renewable energy scenario, the contribution of renewable energy sources is expected to increase very significantly to $47 \%$. It provides an excellent opportunity for the mitigation of Greenhouse gas emission and reducing Global warming. Sun is the ultimate source of all energies and available in plenty. Worldwide solar Photo Voltaic (PV) power is expected to exceed $500 \mathrm{GW}$ capable of producing roughly 4 percent of the worldwide electricity demand. Above all, excessive consumption of fossil fuels not only leads to an increase in the rate of diminishing fossil fuel reserves but also has a significant adverse impact on the environment resulting in global climate change [4]. The world is slowly moving towards seeking more sustainable 
production, reduced air pollution, conservation of nature and reduction of greenhouse gas emissions

\section{Renewable Energy Sources}

Almost three-quarters of new electricity generation facilities built in the year 2019 uses renewable energy, representing an all-time record. The International Renewable Energy Agency (IRENA) shows that solar, wind and other green technologies now provide more than one-third of the world's power, making another record. According to the IRENA, the world has invested about US \$3tn in renewable energy over the past decade, but it should double by 2030 to tackle the climate emergency. IRENA data shows that the renewable energy produced in 2019 was 179 GW. Solar and wind power are now the cheapest forms of electricity in the two-thirds of the world. More than $36.9 \%$ of the UK's electricity was generated from renewable energy resources in 2019, a record for the sector which has resulted in a fall in greenhouse gas emission and the UK moves away from fossil fuels to reach zero pollution as fast as possible. According to IRENA, renewable energy deployment needs to grow even faster, to ensure that we can achieve global climate objectives and Sustainable Development Goal, SDG 7 of the United Nations. Renewable energy sources have the potential to provide energy services with almost zero emissions of greenhouse gases.

\section{Solar Energy}

As far as renewable energy sources are concerned, solar energy is the most abundant one and is available in plenty. The sun emits energy at the rate of $3.8^{*} 1023 \mathrm{~kW}$ of which approximately $1.8 * 1014 \mathrm{~kW}$ is intercepted by the earth [10]. It is the cleanest sustainable, renewable and ecofriendly energy source. Solar energy produces lesser CO2, The carbon footprint of solar is lower than coal and gas. Solar energy works out to about $50 \mathrm{~g}$ of $\mathrm{CO} 2$ per kWh compared to coal which produces $975 \mathrm{~g}$ of $\mathrm{CO} 2$ per kWh. So solar energy is 20 times cleaner than fossil fuels. It has been estimated that $6.6 \mathrm{~kW}$ solar system will produce around 10,600 kWh a year which will save around 10.6 tons of CO2 emission per year. Hence, a solar system, well-installed will make a huge contribution in lowering CO2 emission [11].

\section{Solar Power in KARE Campus}

KARE which is situated in the foothills of the Western Ghats in India in a vast open sky area has implemented various projects on renewable energy resources such as solar energy and biogas energy. Solar panel with the capacity of $800 \mathrm{~kW}$ has been installed in KARE (Table1; Figure 1) which is generating power to the tune of $4000 \mathrm{kWh} /$ day. One hundred and twenty solar street lights with the capacity of $20 \mathrm{~W}$ each and 50 Street lights with $40 \mathrm{~W}$ each have also been erected in the campus to minimize $\mathrm{CO} 2$ emission (Figure 2). These solar sources in the KARE campus helps in lowering the $\mathrm{CO} 2$ emission (Table 3 ). 
Table1. Solar Energy Plants in KARE campus

\begin{tabular}{clc}
\hline S.No & \multicolumn{1}{c}{ Location } & Capacity $(\mathrm{kW})$ \\
\hline 1 & 5th Block & 98.48 \\
2 & 8th Block & 130.60 \\
3 & 9th Block & 135.92 \\
4 & Admin Block & 104.54 \\
5 & Library Block & 146.00 \\
6 & TIFAC Core Block & 184.68 \\
\hline 7 & Total & 800.22 \\
\hline 8 & Solar Street Light 40W & 50 Nos. \\
\hline
\end{tabular}

This solar energy production meets nearly $40.2 \%$ of the total electricity consumption leading to the reduction in carbon footprint (Table 2). As a result, campus is pollution free.
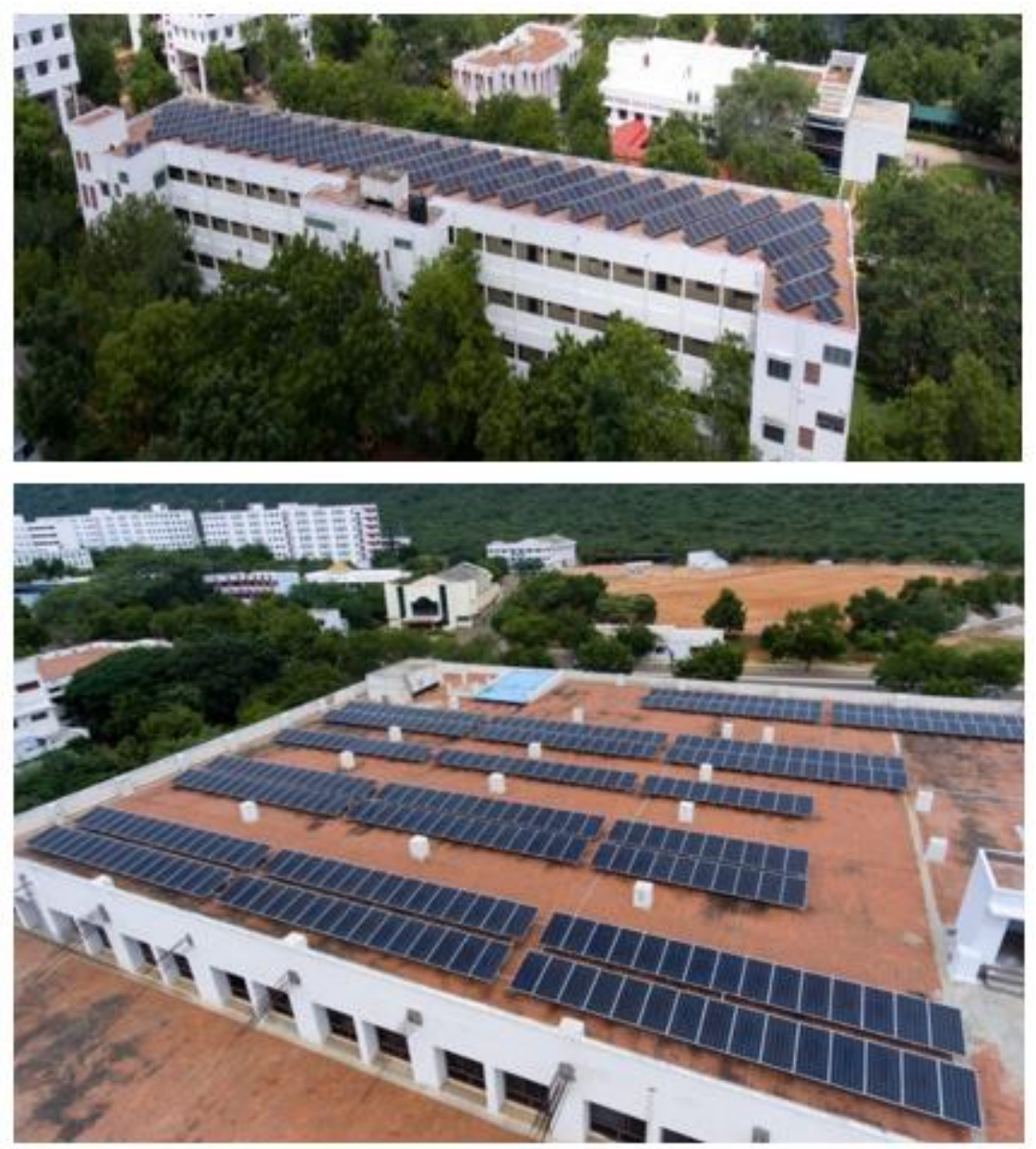

Figure 1: Solar panels installed inside the campus 


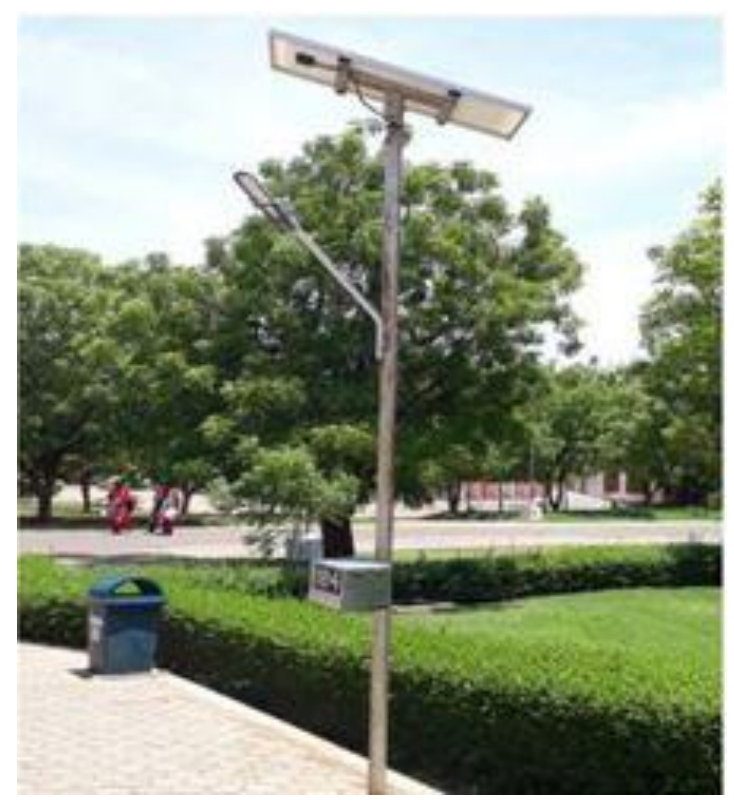

Figure 2: Solar Street Light installed inside the campus

Table 2. Percentage of electricity drawn from solar power for 2019

\begin{tabular}{lcc}
\hline $\begin{array}{c}\text { Calender Year } \\
(2019)\end{array}$ & $\begin{array}{c}\text { High Tension Electricity } \\
\text { consumed (kWh) }\end{array}$ & $\begin{array}{c}\text { Solar Power Generated } \\
(\mathrm{kWh})\end{array}$ \\
\hline January & 234212 & 136803 \\
February & 350253 & 135238 \\
March & 358075 & 171242 \\
April & 378812 & 151169 \\
May & 260652 & 142211 \\
June & 191592 & 105809 \\
July & 319205 & 110939 \\
August & 375043 & 122280 \\
September & 397145 & 94209 \\
October & 316613 & 57533 \\
November & 348993 & 133600 \\
December & 139354 & 98967 \\
\hline Total & $\mathbf{3 6 6 9 9 4 9}$ & $\mathbf{1 4 6 0 0 0 0}$ \\
\hline & $=1460000 \mathrm{kWh}$ \\
Solar Power Generation by solar plant (per Annum) & $=15841 \mathrm{kWh}$ \\
Solar Power Generation by solar street light (per Annum) & $=1475841 \mathrm{kWh}$ \\
Total Solar Power Generation (per Annum) & $=3669949 \mathrm{kWh}$ \\
Total electricity power consumption (per Annum) & $=\mathbf{4 0 . 2 \%}$ \\
\% of power generation through solar plant &
\end{tabular}


Table 3. Details of $\mathrm{CO}_{2}$ emission saved due to solar plants

\begin{tabular}{clc}
\hline S.No & \multicolumn{1}{c}{ Location } & $\begin{array}{c}\mathrm{CO}_{2} \text { emission saved } \\
\text { (kg/annum) }\end{array}$ \\
\hline 1 & 5th Block & 33655.98 \\
2 & 8th,9th \& Admin Block & 69733.31 \\
3 & Library Block & 65645.24 \\
4 & TIFAC Core Building & 8934.44 \\
\hline
\end{tabular}

\section{Carbon Footprint}

Climate change is one of the primary concerns and the greatest challenge in the 21st century [6], which is reflected in SDG13 of the United Nations. The carbon footprint is one of the conventional environmental indicators used to evaluate the environmental impacts associated with a process. Carbon footprint is a measure of the exclusive total amount of carbon dioxide (CO2) emissions that are directly and indirectly caused by an activity. Solar energy used Photovoltaic arrangement is one of the vital non-conventional energy sources which helps to reduce greenhouse gas emission [7]. The production of solar modules still has potential environmental impacts; especially regarding CFC. It is well known that if conventional thermal power plant electricity is replaced by the solar power system, the carbon emission and environmental pollution can be massively declined. The use of cleaner energy sources, such as photovoltaic solar energy, significantly contributes to a reduction of the carbon footprint. Profit-making electricity production at irradiation of $1700 \mathrm{kWh} / \mathrm{m} 2$ year shortens the energy payback time significantly than the expected lifetime of 30 years. Based on a past study[8], the photovoltaic solar panels installation disclosed a clear prospective to lessen change in climate, with negative emissions of $-207.88 \mathrm{~kg} \mathrm{CO2-eq/year,}$ compared to positive $789.36 \mathrm{~kg} \mathrm{CO}-\mathrm{eq} / \mathrm{year}$ linked with consumption of electricity from the government electric grid. Gulf countries accelerated the pace of shifting to large PV technology projects. Besides this decision helps the countries for the reduction in the carbon footprint and further cost of the solar energy, many new industries will grow such as battery storages for PV electricity, cost-effective air conditions and devices which enhance green job and green economy[9].

\section{Carbon foot print for solar energy for the calender year 2019 (For KARE Campus):}

Installed Capacity

Power produced/ annum (solar plant)

Power produced/ annum (solar street light)

Total Power Produced

Total number of people in the campus

Total $\mathrm{CO} 2$ emission reduction

Carbon foot print for Solar energy

Carbon foot print per capita per annum

$$
\begin{aligned}
& =800 \mathrm{~kW} \\
& =1460000 \mathrm{kWh} \\
& =15841 \mathrm{kWh} \\
& =1475841 \mathrm{kWh} \\
& =7,500 \\
& =1343.2 \mathrm{tCO} 2+42.705 \mathrm{tCO} 2 / \mathrm{MWh} \\
& =1385.905 \mathrm{tCO} 2 / \text { annum } \\
& =0.1847 \mathrm{tCO} 2
\end{aligned}
$$

\section{Energy efficient appliances in reduction of $\mathrm{CO} 2$ emission in KARE campus:}

Energy efficient appliances are installed in the campus wherever replacement is done. The energy efficient appliances are installed whenever replacement is done in all 
areas like, lightings, Air conditioners, fans and Geysers. So far a total number of $250 \mathrm{slim}$ tube lights of $28 \mathrm{~W}$ in place of $40 \mathrm{~W}$ tube lights and 200 no of $18 \mathrm{~W}$ LEDs in place of 200 no of $40 \mathrm{~W}$ tube lights have been installed. Star rating A/c and Geysers are installed. 756 Super fans are installed in place of old fans which results in the reduction of $\mathrm{CO} 2$ emission in the campus (Table 4).

Table 4. Energy Efficient Appliances in KARE campus

\begin{tabular}{clc}
\hline S.No & Appliances & $\begin{array}{c}\mathrm{CO}_{2} \text { emission saved per } \\
\text { annum }\left(\mathrm{tCO}_{2}\right)\end{array}$ \\
\hline 1 & Lightings & 15.54 \\
2 & Air conditioners & 25.634 \\
3 & Super Fans & 74 \\
\hline & Total & 115.174 \\
\hline
\end{tabular}

\section{Green vegetation in KARE campus as Carbon Sink}

About $40 \%$ of the area on the campus of KARE is covered with green vegetation (Figure 3). This green vegetation takes up more carbon from the atmosphere, as a result of increased photosynthesis, a process known as $\mathrm{CO} 2$ fertilization which leads to reduction in carbon level in the campus. These green plants are the carbon sinks. Carbon sinks are natural or artificial deposits that absorb and store carbon from the atmosphere helping reduce the greenhouse effect [12].

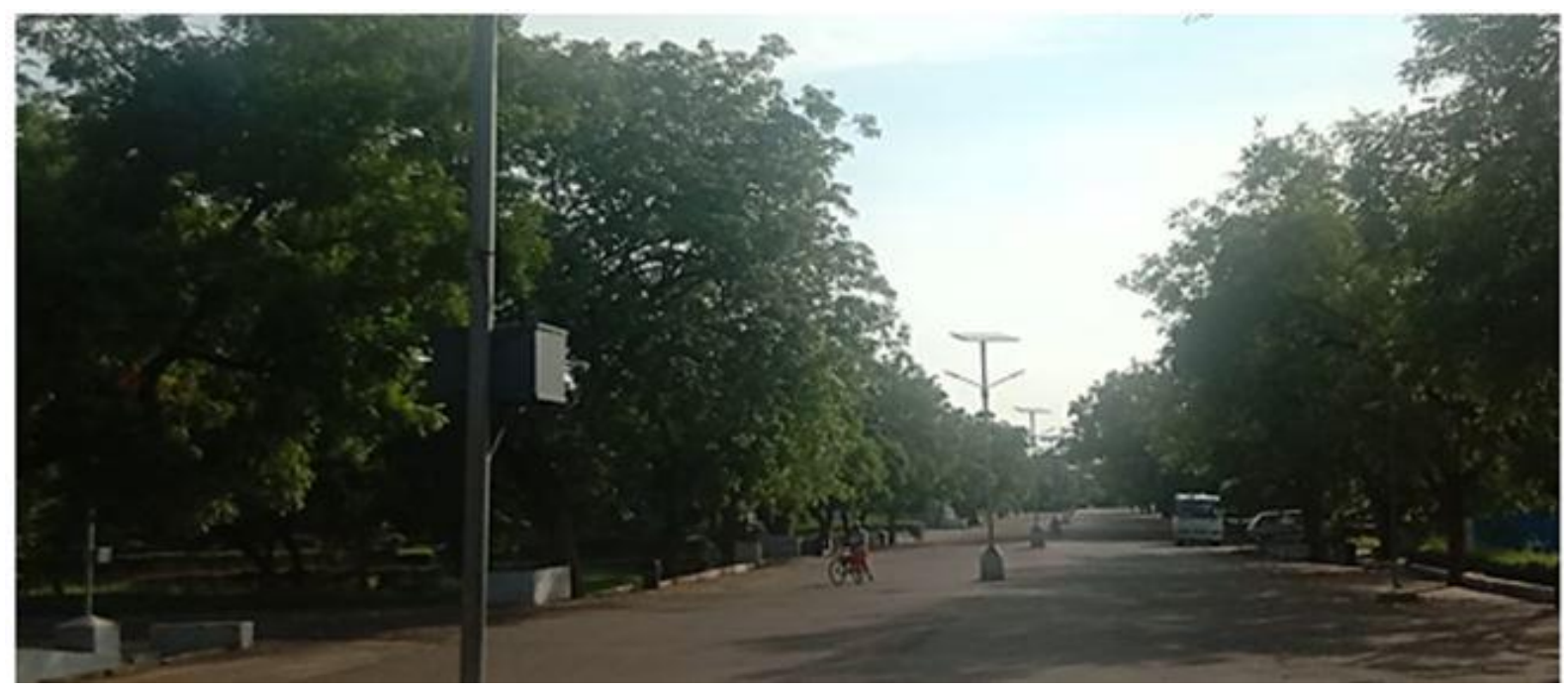

Figure 3: Green vegetation inside the campus

\section{Conclusion}

A comprehensive literature survey of solar energy system and green plants as source of carbon sink was made. The review gives an overview of the development and scope of CO2 mitigation for clean, pollution free, ecofriendly environment and sustainable development. The use of solar power has good potential for reducing the $\mathrm{CO} 2$ emission. As far as KARE is concerned, $800 \mathrm{~kW}$ of solar panel has been installedwhich not only meets around $40 \%$ total electricity consumption but also 292.174 tons of $\mathrm{CO} 2$ emission per year is also saved. About $40 \%$ of the area in the campus is greenery which is the source of carbon sink as the plants are the most efficient carbon sink in nature. It is inferred that by going 
solar, one can reduce demand for fossil fuels to overcome the energy crisis, limit greenhouse gas emissions and shrink the carbon foot print. This paper explicitly points out the $\mathrm{CO} 2$ gas emission mitigation potential depending on the use and availability of solar energy and green vegetation in the campus. It is concluded that it is important to follow $5 R$ rules to protect our environment. They are Refuse, Reduce, Reuse, Repurpose and Recycle. These $5 R$ rules are followed in our KARE campus to keep the environment clean, ecofriendly, pollution free and sustainable. These are the best practices which are adopted in KARE campus

\section{References}

1. UNDP Worlds energy Assessment 2010 - Energy and the challenge of sustainability New York: UNDP 2010.

2. Dincer. I. Environmental Issues II Potential Solutions Energy sources Recovery, utilization and Environmental effects 2011 23(1) 83-92.

3. Bilgen.S.Kaygusuz K.Sari A.Renewable energy for a clean and sustainable future Energy sources Recovery utilisation and environmental effects 2004 26(12): 1119-1129.

4. Farhad S Saffar. Avval M, Younassi sinaki, Efficient design of feed water heaters network in steam power plants using pinch technology and energy analysis. International Journal of Energy Research 2008,32:1-11.

5. Youm I, Sarr J, Sall M, Kane MM Renewable energy activities in senegal: a review Renewable and sustainable energy Reviews 2010:4(1):75-89.

6. Tingem $M$, Rivington $m$, Adaptation for crop agriculture to climate change in cameroon turning on the heat mitigation and adaptation strategies for global changes 2009:14:153-168

7. Tum. A novel loT based dynamic carbon footprint approach to reduce uncertainties in carbon footprint assessment of a Solar PV supply chain.2017:1-5.

8. Mayara et al., M. Grid carbon footprints for the supply of electricity to a heat pump. Solar Energy vs Electric Grid 2018:023701:111-115.

9. Ntinas,G.K., Dannahl,I, Schuch,T, Rocksch and Schmidt,U.Science Direct 2018.

10. Thirugnanasambandam $M$. Iniyan S. Goic $R$ A review of solar thermal technologies Renewable and Sustainable Energy Reviews 2010:14:312-321

11.Panwar,N.L, Kaushik,S.C.Surendra Kothari Role of renewable energy sources in Environmental protection: A review. Renewable and sustainabe energy reviews 2011:15:1513-1524.

12. Melanie Fried L, Forests as carbon sinks, American Forests: 2017:101-117 